\title{
Energy Management and Renewable Energy Sources - Rubber Anaconda
}

\author{
N.Alamelu ${ }^{1}$, M. Mariya Shyamala ${ }^{2}$ P.K.R.Pavithra ${ }^{3}$ N.Sowmia ${ }^{4}$, \\ S.Leena Sushmidha ${ }^{5,}$ V.Kavitha ${ }^{6}$ \\ ${ }^{1} U G$ Scholar, Department of Electrical and Electronics Engineering, Narasu's Sarathy Institute of Technology, \\ Salem-636455. \\ ${ }^{2,3,4,5,6}$ UG Scholar, Department of Electronics and communication engineering, K.S.R College of engineering,
} Tiruchengode-637211

\begin{abstract}
In our enhancing world power production is very less and the power production causes many factors. So we should manage power with efficient way and should reduce power wastage. Use the power in proper manner. And also we need a source that will not affect our environment. Need of power in our world is very high, so for producing electricity some renewable energy sources are required. This type of renewable source is "RUBBER ANACONDA". Wave power is used to produce electricity from this rubber anaconda. Let us peep inside the real world of Rubber Anaconda.

This is one of the renewable energy using wave power. In this a rubber tube is used to produce power. In the rubber tube both ends are closed and one end of the tube connected with turbine and generator. Wave energy from the sea is converted inside the rubber as kinetic energy. This kinetic energy is used to drive the turbine and the turbine shaft is connected with the generator from that we produce electricity. This electricity is taken outside via cable.

The production of power by using this anaconda is very low cost. Electricity produced from anaconda is capable of supplying power for more than 2000 houses. Since water in the sea will not shrunken till the end of the mankind, the production of power will be continuous.
\end{abstract}

\section{Introduction:}

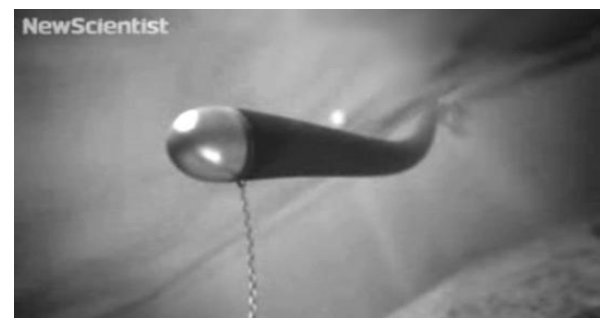

Fig: structure of rubber anaconda

Effective energy management is necessary in energy consumption field... We should use electricity with careful way. Now our requirement is a novel renewable energy with low cost. The rubber anaconda is a new renewable Wave Energy source. The project is very important for our future generation. Anaconda has shown considerable promise compared with other Wave energy conversion sources. Anaconda's method of operation and construction mean that it has enormous potential, potential which exceeds all other wave energy converters and many other renewable energy sources.

\section{Energy Management:}

Now there is power demand in our country. We waste more power without proper energy management. So we should save energy. There is some of idea for good energy management. Those are all given below:

1) In our world power theft from transmission line is high. In India 30\% of power production is wasted by this way so government should take proper action.

2) We use ac power transmission leads more power loss. So use HVDC transmission in power sector.

3) Use the generator in full load condition it gives more efficiency.

4) Use parallel connection of shunt generator it will give high efficiency.

5) Use ISI standard electrical\& electronics things it can save power.

6) Use proper illumination on the lights.

7) Use capacitive load instead of inductive load.

8) Switch off unwanted lights and fans in our college also our home. 
Energy Management And Renewable Energy Sources - Rubber Anaconda.

9) Be an electrical engineer should save the power.

In next paragraph we will present anaconda, which is not yet in commercial use.

\section{Principle:}

JUST A RUBBER TUBE IN THE SEA .... . full of water, closed at both ends, anchored head to waves. In this picture the waves come from the left.

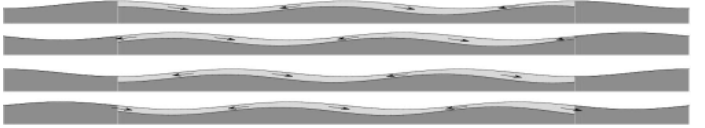

The arrows show the oscillating flow of water inside the tube. The velocity of the bulge wave [A good example is the pressure pulse which travels along your arteries.]In the tube and the waves in the sea is the same; then the wave energy is transferred gradually to the tube. At the bow, the wave squeezes the tube and starts a bulge running. But as it runs the wave runs after it, squeezing more and more, so the bulge gets bigger and bigger. The bulge runs in front of the wave where the slope of the water (pressure gradient) is highest. In effect the bulge is surfing on the front of the wave.

The wave power over a wide frontage is concentrated at the end of the tube. We can use it to drive a turbine, generate electricity or pump water.

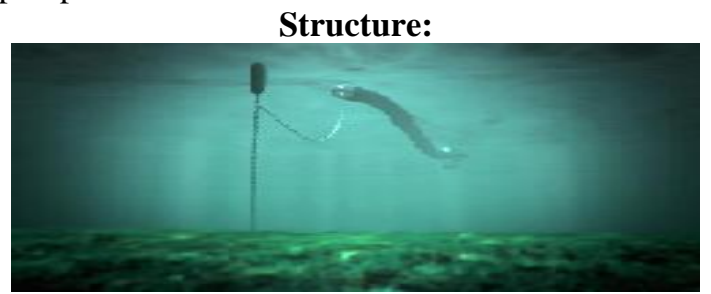

Fig: rubber anaconda in water.

Future full-scale Anaconda devices would be $\mathbf{2 0 0}$ meters long and 7 meters in diameter, and deployed in water depths of between 40 and 100 meters. An Anaconda would deliver an output power of $1 \mathrm{MW}$ (enough to power 2,000 houses). These devices would be deployed in groups of 20 or even more providing cheap electricity without harming our environment.

\section{Working:}

Anaconda uses an entirely novel concept to harvest wave energy. This resource is free and widely available to the UK and Eire as well as other countries with west facing ocean seaboards. The inventors (Professors Rod Rainey and Francis Farley FRS) have developed the concept of a distensible rubber tube, floating head to sea, in which bulge waves are excited by passing sea waves. The bulge waves are then used to drive a turbine generator. It is the long ocean swells which have most energy; developed by winds over hundreds or thousands of miles; these are the ones Anaconda uses. This is a particularly rich, but as yet untapped, energy resource which Government studies state could produce 3\% - 5\% of our electricity initially and up to $20 \%$ eventually.

The Anaconda team has now developed the concept in the most rigorous way to produce information which shows that Anaconda has the potential to be one of the most cost effective sources of renewable energy. We are now embarking on a research and development programmer which will develop the system and demonstrate what Anaconda is capable of.

Essentially, it is a very large (perhaps $200 \mathrm{~m}$ long and $5 \mathrm{~m}$ diameter) water filled distensible rubber tube floating just beneath the ocean surface at right angles to the waves, with a power take off at the stern. As a long wave passes the bulge tube is lifted with the surrounding water and this causes a bulge wave to be excited which passes down the tube's walls like a pulse in an artery, gathering energy from the ocean wave as it goes. Continuous energy gathering is caused by resonance between the bulge wave frequency and the sea wave's so energy is drawn in towards the tube from the width of the sea wave crest as it progresses along the tube. Energy from the sea wave is stored in the rubber as potential energy by it being stretched (in a sea wave it is stored as potential energy due to gravity). The bulge wave travels just in front of the wave rather like a surfer, picking up energy as it increases progressively in size. At the end of the tube the bulge wave energy is converted to a surge of water which drives a turbine in the power take off after the flow has been smoothed.

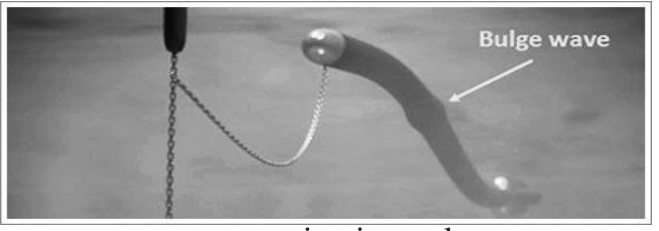

Www.iosrjournals.org 
Water from each bulge wave flows under pressure into the upper reservoir of the Power Take Off through a one way valve. Energy storage is due to potential energy against gravity because the reservoirs are at different heights. The space above the free surface in each reservoir is occupied by a variable volume air bag. These are interconnected and used to maintain a positive pressure in the system. Pressure compensation due to the system pressure being higher then the surrounding sea allows the water to flow under gravity through the turbine and into the lower chamber. As water leaves the upper chamber, air from the lower chamber's air bag goes in the opposite direction to fill the upper chambers so the total volume of the two reservoirs remains the same. The water is then drawn back into the bulge tube through the other one way valve during the low pressure phase of the bulge wave. Since they are inter-connected, pre-pressurisation of the bulge tube is achieved by the compensation system used in the PTO. This allows the bulge tube to contract beyond its resting state without becoming flaccid. Another benefit of the pre-pressurisation is that it keeps the distensible portion of the bulge tube in tension, greatly increasing its fatigue life. Pressurisation also affects tuning to the sea wave length. Reactor mass is provided by the water in the PTO and there is an additional keel weight which is also used for stability.

\section{How to Control?}

Typically a rubber tube filled with water will bulge locally when squeezed; and this bulge will propagate along the tube at a speed $\mathrm{C}$ given by,

$$
\mathbf{c}^{2}=\frac{E \mathbf{h}}{\mathrm{dp}}
$$

Here $\mathrm{E}$ is the tensile modulus of the rubber, $\mathrm{d}$ the diameter of the tube, $\mathrm{h}$ its wall thickness and rho is the density of water. You can control the speed by choosing the dimensions of the tube and the properties of the rubber.

The bulge wave is a wave of pressure, associated with a longitudinal oscillation of fluid, forwards and backwards along the tube. When the pressure is high, the water is flowing forwards; when it is low the water is flowing backwards. This wave carries energy.

The mathematics of a bulge tube in the sea has been worked out. If the bulge in the tube travels at the same speed as the wave, then there is a resonant interaction and the bulge grows linearly along the tube.

\section{RUBBER ANACONDA IN FUTURE:}

The anaconda could make a valuable contribution to environmental protection by encouraging the use of wave power .A one-third scale model of the anaconda could be built next year for sea testing and the world will see the first full -size device deployed off the UK cast in around five years time.

The Anaconda is, however, still at an early stage of development. The concept has only been proven at very small laboratory-scale, so important questions about its potential performance still need to be answered. Funded by the Engineering and Physical Sciences Research Council (EPSRC), and in collaboration with the Anaconda's inventors and with its developer, engineers at the University of Southampton are now embarking on a program of larger-scale laboratory experiments and novel mathematical studies designed to do just that pressurised and sealed on both sides.

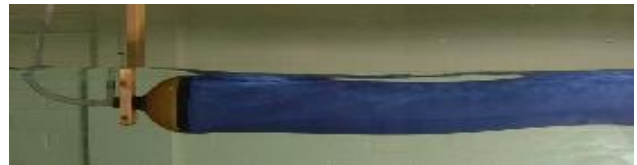

Fig: Rubber anaconda

\section{Small Scale Testing:-}

Fig: Photographs of the anaconda in a narrow tank. Currently only small scale models of Anaconda were built for laboratory tests. Experiments are concentrated to the tube part, so no testing has yet been made for the power extracting part. One prototype measures $2.5 \mathrm{~m}$ in length and $7.8 \mathrm{~cm}$ in diameter. Rubber thickness is $0.15 \mathrm{~mm}$, which provides resonance at $\mathrm{c} 0=1.93 \mathrm{~m} / \mathrm{s}$. The experiments were made in a tank, several times wider than the tube. Pure harmonic waves were produced by simple flapping motion on one side. Remaining waves were absorbed at the opposite side of the tank, to prevent interference of reflected waves. The tube was that losses are not problematic if we keep strains within reasonable limits. 


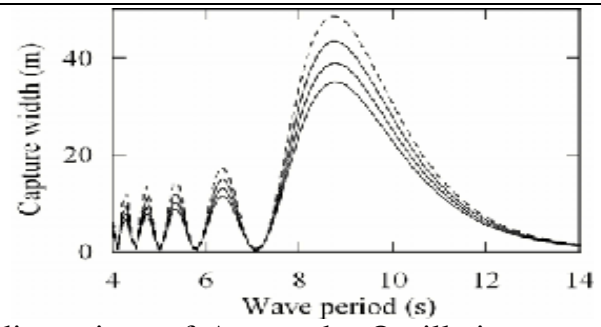

Fig: Capture width for proposed dimensions of Anaconda. Oscillations are caused by interference of external waves and bulge waves.

\section{Cost And Profit:}

The only capital cost of Anaconda is the large amount of rubber, needed for the tube. Proposed size for operational version of the device is $150 \mathrm{~m}$ long and $7 \mathrm{~m}$ in diameter. This equals several hundred tons of rubber. The smaller variation with $1.5 \mathrm{~m}$ diameter would produce $50 \mathrm{~kW}$ of power at slightly higher cost.

\section{ADVANTAGE:}

1) Millions Of tons of carbon dioxide production around the world is reduced.

2) It produces roughly electricity consumption of $\mathbf{2 0 0 0}$ houses.

3) It is a closed circuit system so issues with ingestion of marine animals will not arise. Because it is under the surface and rubber can be formulated to be none polluting, environmental impact will be minimal.

4) Although around twice as much as coal-fired power stations, this compares very favorably with other leading wave energy concepts.

5) Its ultra-simple design means it would be cheap to manufacture and maintain, enabling it to produce clean electricity at lower cost than other types of wave energy converter.

6) Rubber tubes can live forever in the sea. Anaconda won't break no hinges, no joints ... and it's cheap!

7) Which has the potential to produce a significant amount of clean "green" energy? While it certainly will not solve all of the West's energy problems, it could be a significant step toward reducing dependency on fossil fuel.

8) We can reduce "global warming".

\section{COMPARISION BETWEEN OTHER SOURCES:}

1) Compare to thermal power plants there is no air pollution.

2) It is not depend on weathering compare to hydrological power plant.

3) Comparing to nuclear power plant it is non-hazardous.

4) Compare to solar power plant it has high efficiency.

5) Rubber anaconda placed in-depth of $40 \mathrm{~m}-100 \mathrm{~m}$ so there is no problem in Marine transport comparing to tidal power plant.

\section{Conclusion:}

The power production also makes pollution, so we need a novel renewable power generating source that should not affect our earth. This type of a new source is this "RUBBER ANACONDA".

After some decay the coal present in world will expire, and also in future we need more electricity for increasing population. Renewable energy is the only solution for producing required amount of power generation with low cost. The rubber anaconda satisfies all this facts. Using this we can produce continues required amount of power with low cost and with out pollution comparing to other sources. And high efficiency compare to other renewable sources. From that we can conclude this is one of the best renewable energy sources with out any pollution.

\section{References:}

[1] Farley, F.J.M., 1982 Wave energy conversion by flexible resonant rafts Appl. Ocean Res, 4 1, 57-63

[2] Farley, F.J.M., 2006 Buckling beam wave energy converter. British Patent Application

[3] Farley, F.J.M. \& Rainey, R.C.T., 2006 Distensible tube wave energy converter. British Patent Application

[4] Lamb, H. 1932 Hydrodynamics, 6th Ed. CUP.

[5] Lighthill, M.J. 1978 Waves in Fluids. CUP. 